\title{
¿NEUTRALIDAD O PLURALISMO \\ EN LA APLICACIÓN DEL DERECHO? INTERPRETACIÓN JUDICIAL E INSUFICIENCIA DEL FORMALISMO ${ }^{1}$
}

\section{Texto y contexto}

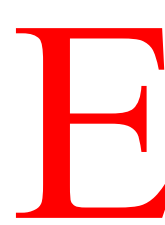

$\mathrm{n}$ este trabajo se pretende reflexionar sobre el tipo o la calidad de la aproximación que el texto de la ley permite hoy al juez-intérprete. Con ese fin se toma en consideración, no sólo el modo de ser ideal de aquél, sino también el antimodelo que halla cada vez mayor grado de realización en la producción legislativa que nos abruma (y que, como se verá, encuentra en un lamentable texto legal reciente una expresión ciertamente paradigmática). Se tiene en cuenta, asimismo, una dimensión de la actividad judicial -la relativa a la quaesio facti- escasamente atentida, cuando paradójicamente es la que permite al juez mayor uso de la discrecionalidad. $\mathrm{Y}$, en fin, se atiende a algunas otras particularidades del marco en que se desarrrolla en la actualidad la aplicación judicial del derecho (preferentemente del derecho punitivo), que contribuyen hoy a hacerla notablemente problemática y resistente al viejo intento de tipificación desproblematizadora. Todo ello, con la pretensión de contribuir, siquiera sea tendencialmente, a hacer más visibles algunos momentos de poder relativamente ocultos, en el ejercicio de la jurisdicción y éste más transparente y asequible a formas de control racional compatibles con el principio de independencia.

Con ese fin, se parte de una opción de campo consistente en situar la exposición en el terreno de la que, con palabras de Luigi Ferrajoli, llamaré «interpretación operativa»; o sea la que «tiene por objeto, más que las normas, las concretas experiencias jurídicas en las que el ope-

${ }^{1}$ En 1992, días 24-26 de septiembre, fui invitado por Roberto Bergalli a intervenir en el IV Congreso Español de Sociología, dentro del área de sociología del Derecho, con el tema «¿Neutralidad o pluralismo en la aplicación del derecho?». El presente texto conserva ese título, por su expresividad, y tiene aquella exposición como punto de partida. 
rador, se encuentra personalmente implicado e interesado, en cada ocasión $»^{2}$. O si se quiere, el juego de la norma en la experiencia de su aplicación -aquí, preferentemente judicial- al caso concreto.

En definitiva se trata de discurrir acerca del papel de un determinado tipo de intérprete, como agente de la mediación entre un texto y un contexto. Tomando aquí «texto», no en el sentido que le da Van Dijk ${ }^{3}$, de construcción teórico-abstracta, que preexiste al y se actualiza en el «discurso» interpretativo. Porque el jurista operativo no actúa a partir de un «texto» así entendido como «monólogo», en la medida en que, como ha escrito Ross, «la interpretación no tiene punto de partida lingüístico independiente» ${ }^{4}$; sino, antes bien sobre algo más próximo a la idea del «discurso interactivo»", sobre un complejo integrado no sólo por la disposición o disposiciones legales -con sus problemas específicos, a los que aludiré-, sino también y a la vez por una situación fáctica, por un conjunto de datos empíricos. Una(s) y otra, que se interpelan recíprocamente, tienen que ser leídas en esa relación de mutua implicación, en la que ya se encuentran desde el comienzo de la operación que nos ocupa. Relación en la que la norma es «lenguaje en uso», instrumento «para la solución de problemas prácticos» ${ }^{6}$.

Por «contexto» se toman ciertos datos de la realidad, de particular incidencia en la tarea de que se trata: la inevitable colocación del juez-intérprete en el marco de algunos parámetros de naturaleza político-cultural (hoy, a veces, directamente política) y también de carácter institucional ${ }^{7}$; la dimensión constitutivamente conflictual

${ }^{2}$ L. Ferrajoli, «Interpretazione dottrinale e interpretazione operativa», Rivista Internazionale di Filosofia del Diritto, I/1966, pág. 292.

${ }^{3}$ T. A. Van Dijk, Estructuras y funciones del discurso, trad. de M. Gann y M. Mur, Siglo XXI, México, $7^{\mathrm{a}}$. ed. 1991, págs. 19-21.

${ }^{4}$ A. Ross, Sobre el derecho y la justicia, trad. de G. R. Carrió, Editorial Universitaria de Buenos Aires, 2a . ed., 1970, pág. 140.

${ }^{5} \mathrm{Cfr}$. M. Stubbs, Análisis del discurso. Análisis sociolingüístico del discurso natural, trad. de C. González, Alianza Editorial, Madrid, 1983, págs. 23-24.

${ }^{6} \mathrm{M}$. Barberis, Il diritto come discorso e come comportamento, Giappichelli editore, Turín, 1990, págs. 90 y 97.

${ }^{7}$ Puede verse en Elías Díaz, «Escrito preliminar a la edición española» de: Renato Treves, El juez y la sociedad, trad. de F. Laporta y A. Zaragoza, revisada y anotada por L. Mosquera, Edicusa, Madrid, 1974, pág. 8, una temprana demanda de atención a estas variables como precondición para comprender la verdadera realidad del trabajo del juez. 
del tema sometido, en cada caso, a su consideración; la necesidad de dar una solución -que responda idealmente a la verdad de los hechos-, plausible en términos empíricos, a un problema, mediante la aplicación de un precepto.

Parece innecesario decir que ambos niveles de reflexión resultan ser hoy especialmente problemáticos. Y no sólo porque presentan aspectos teóricos de interés. Sino -y diría que, ahora, sobre todo- porque en ellos se expresan cuestiones de evidente alcance práctico-político.

«El problema de la interpretación tiende, pues, a hacer emerger, como un componente propio, el problema del papel del jurista, en particular del juez», escribía Pietro Costa $^{8}$. Para señalar, como en ese campo, al menos relativamente pacífico en algún momento anterior, fueron a proyectarse después en toda su crudeza ciertas vicisitudes de la instancia judicial, que, puesto que se producen en su interrelación con las demás instancias políticas y en su modo de relacionarse también con la propia sociedad, son una parte de las relativas al gobierno de esta última. Atañen a las vicisitudes -la crisis, o, si se quiere, la situación crítica-, en suma, que atraviesa el vigente modelo de Estado.

\section{Inviabilidad de una concepción «hidráulica» del derecho}

Volviendo a las cuestiones del texto, parecería que la amplia aceptación de opiniones como la ya clásica de Carrió, de que «la indeterminación marginal del orden jurídico es algo con lo que tenemos que contar» ${ }^{9}$; o la bastante más reciente de Luzzati de que la imprecisión del significado de las palabras, con referencia a las normas, es algo que «ni siquiera los métodos más sutiles de reducción de la vaguedad son capaces de eliminar completamente» ${ }^{10}$; podrían tomarse como síntoma de una definitiva superación del punto de vista de formalismo dogmático ${ }^{11}$.

${ }^{8} \mathrm{P}$. Costa, «La alternativa «presa sul serio»: manifesti giuridici degli anni settanta», en Democrazia e diritto, 1-2/1987, pág. 20. (Trad. castellana en «Italia, años 80. Derecho, política y democracia», Anales de la Cátedra Francisco Suárez, no. 30/1990. 70.

${ }^{9}$ G. R. Carrió, Notas sobre derecho y lenguaje, Abeledo-Perrot, Buenos Aires. 2a . ed. 1979, pág.

${ }^{10}$ C. Luzzati, La vaghezza delle norme, Un'analisi del linguagio giuridico, Giuffrè, Milán, 1990, pág. 95.

${ }^{11}$ Uso aquí «formalismo» en el sentido en que lo hizo Scarpelli, «Introduzione all'analisis delle argomentazioni iudiziarie», en Diritto e analisi del linquaquio, ed. del autor, Edizioni di Comunita, Milán, 1976, que calificaba de «formalista» a aquel que, «entre los juristas, considera que el lenguaje jurídico, en el que el derecho se expresa, tenga una lógica autosuficiente e íntegramente determinante de las operaciones de interpretación y de aplicación del derecho mismo» (pág. 409). 
Pero éste no deja de hacerse patente, con frecuencia de manera implícita, pero también explícitamente en ocasiones. Tal es, entre nosotros, el caso de Requejo Pagés, sumamente ilustrativo, como expresión de lo que el propio Scarpelli ${ }^{12}$ considera un radicalismo con escasa presencia en los medios científicos. Pero que, a mi juicio, permanece vivo en la percepción que se tiene del propio rol en un amplio sector, el más tradicional, culturalmente y políticamente hablando, de la magistratura ${ }^{13}$.

Concibe ese autor el ordenamiento como un sistema cerrado que, "sin necesidad de recurrir a nuevos datos que le son externos, sino sirviéndose de los que ya puede proporcionarse, se desumbilica de su entorno y funciona por sí mismo cumpliendo el cometido que le corresponda, en el caso de los sistemas jurídicos, ordenando conductas». Después, asimila el «sistema jurídico» a «una red de distribución de agua». Para concluir, apurando el pueril símil hidráulico, que «el juez debe limitarse a recoger en el continente de sus resoluciones el producto que le llega desde las primeras fases del ordenamiento. No puede añadirles nada. Si según su parecer el producto con el que se encuentra adolece de algunas insuficiencias, no le está permitido corregir motu propio tales deficiencias. Lo que debe hacer es remitirlo al laboratorio de análisis químicos, es decir al Tribunal Constitucional, único órgano habilitado para enjuiciar la calidad del producto y obligar en su caso a los operadores primarios del sistema a que corrijan las deficiencias por él observadas. Quien clora las aguas no es el juez que abre la llave, sino el legislador que decide la composición del líquido contenido en el depósito ${ }^{14}$.

Desde otra perspectiva, desde luego más atendible, se ha postulado la reserva del término «interpretación» para los supuestos «de duda» («situación de interpretación»); por oposición a los supuestos de «claritas», en los que lo que existe es una «situación de isomorfia» ${ }^{15}$.

Me parece, sin embargo, que cuenta con mayor adherencia a la realidad de la tarea que nos ocupa el punto de vista que, formulado

${ }^{12}$ U. Scarpelli, op. cit., pág. 409.

${ }^{13}$ Se trata también del sector más resistente frente a la exigencia constitucional de motivación de las resoluciones judiciales. Precisamente porque la banalización del momento interpretativo permite a estos jueces autopresentarse como «bouche de la loi», condición ésta donde -para el formalistaradica la garantía.

${ }^{14}$ J. L. Requejo Pagés, Jurisdicción e independencia judicial, Centro de Estudios Constitucionales, Madrid, 1989, págs. 111 y 153-154.

${ }^{15}$ J. Wroblewski. op. cit., pág. 24. 
inicialmente por Tarello ${ }^{16}$, ha expresado también Guastini, y que contrasta abiertamente con el que acaba de aludirse. Para este autor, limitar la existencia de verdadera y propia interpretación a los casos difíciles, nueva versión del in claris non fit interpretatio, es perder de vista que ya la misma distinción entre casos «claros» y casos «oscuros» -que obviamente presupone un acto interpretativo- es discutible. Pero sobre todo, es olvidar que la interpretación no puede entenderse como actividad puramente «cognoscitiva», pues «no existe una cosa como el «significado propio» de las palabras: las palabras tienen sólo el significado atribuido por quien las usa y/o por quien las interpreta. Por tanto, el significado es cambiante, y toda decisión interpretativa es siempre, en alguna variable medida, arbitraria» ${ }^{17}$.

\section{Recuperar la quaestio facti}

Esto, que puede admitirse con carácter general ${ }^{18}$ incluso en una perspectiva meramente textual, es decir, aun situándose en un supuesto hipotético de pura interpretación doctrinal, se hace mucho más patente en el plano de la interpretación operativa, por la incorporación de una concreta cuestión de hecho.

Tal incorporación acontece no como un fenómeno aleatorio, que fuera consecuencia de la eventual aplicación de una regla de derecho a un hecho extra o pre-jurídico, sino como un dato en cierta manera necesario, porque «la norma jurídica y la experiencia prevista por ella no son entrañables una de la otra, sino que, por el contrario, se

${ }^{16} \mathrm{El}$ intérprete pone de relieve, decide, o propone el significado que atribuye a un documento, constituido por uno o más enunciados, cuyo significado no está en modo alguno preconstituido a la actividad del intérprete, sino que es su resultado; antes de la actividad del intérprete, del documento objeto de interpretación sólo se sabe que expresa una o más normas, no cuál sea o cuáles sean esta norma o normas: «norma» significa simplemente el significado que se ha dado, o se ha decidido dar, o se ha propuesto que se dé, a un documento del que se entiende, conforme a indicios formales. que expresa alguna directiva para la acción. (G. Tarello, L'interpretazione della legge, Giuffrè, Milán, 1980, págs. 63-64).

${ }^{17}$ R. Guastini, Dalle fonti alle norme, G. Giappichelli Editore, Turín, 1990, págs.84-86.

${ }^{18} \mathrm{Y}$ entiendo con Ruiz Miguel que, efectivamente, «no deben exagerarse las dificultades de la comunicación lingüística hasta creer que la existencia de lagunas o de ambigüedades en el derecho impida decir que hay decisiones judiciales que aplican y se adecuan a criterios abstractos preexistentes» («Creación y aplicación en la decisión judicial», Anuario de Filosofía del Derecho, 1984, pág. 24). Aunque, quizá por deformación profesional, me gustaría matizar en el sentido de preexistentes en algún grado. 
dan conectadas por una relación semántica. De este modo, en realidad, la eficacia o relevancia de una experiencia jurídica se configura como la significatividad de ésta en términos normativos», porque «no hay un hecho y una norma en espera de ser unidos por un acto de calificación del hecho o de aplicación de la ley. Las proposiciones normativas tienen sentido en cuanto hacen referencia a una experiencia jurídica designada como posible, es decir, en cuanto pueden denotar experiencias jurídicas concretas» ${ }^{19}$.

Así las cosas, en contra de lo representado por una imagen cara a cierta mitología judicial, el juez, como intérprete operativo por antonomasia, no está nunca «solo», pero menos aún «a solas con la ley», frente al caso.

A partir de esta constatación, podría decirse que el grado de complejidad de -y el margen que se abre a- la tarea de atribución de significado crece en proporción directa al grado de proximidad del intérprete a la quaestio facti ${ }^{20}$.

Es decir, al operar, como lo hace el juez, en el marco de un sistema escalonado de instancias, hay siempre un primer momento de máxima contigüidad al segmento de experiencia jurídica sometido a su consideración. En él, se hace preciso entrar -con el lenguaje como único vehículo- en relación directa con los sujetos implicados ${ }^{21}$, con las diversas fuentes de prueba; tomar contacto con la situación a examen, recibiendo así todo un cúmulo de informaciones que deben ser tratadas procesalmente, tamizadas en el juego de las reglas del método probatorio, evaluadas en función de su mayor o menor relevancia o aptitud para integrar un «supuesto de hecho», en cuya construcción como tal el que enjuicia participa de manera a activa ${ }^{22}$.

Naturalmente ese encuentro está también lejos de darse «a solas con los hechos»: de poco serviría tratar de escapar a aquel normativismo ingenuo para caer en cierto ontologismo o inductivismo de equivalente grado de ingenuidad y de irrealidad ${ }^{23}$.

\footnotetext{
${ }^{19}$ L. Ferrajoli, op. cit., págs. $299, \mathrm{n}^{\text {os }} .23$ y 300.

${ }^{20}$ Cfr. al respecto L. Prieto Sanchís, Ideología e interpretación jurídica, Tecnos, Madrid, 1987, pág. 88 .

${ }^{21}$ «Los titulares de las situaciones procesales... dialectizan lingüísticamente las propias posiciones» (M. Menna, Logica e fenomenologia della prova, Jovene Editore, Nápoles, 1992, pág. 3).

${ }^{22}$ Como ha escrito F. J. Ezquiaga Ganuzas, «la imagen (del juez) como mero observador es falsa. El juez construye el objeto...» («Los juicios de valor en la decisión judicial», Anuario de Filosofía del Derecho, 1964, pág. 35).

${ }^{23}$ «Los hechos son complicados, los hechos sociales son los más complicados entre los hechos. El mismo hablar de hechos, como si los hechos estuvieron allí tranquilamente por su cuenta esperando nuestro conocimiento fáctico, es un modo ingenuo de expresarse, que oculta gruesas complicaciones epistemológicas...» (U. Scarpelli, op. cit., pág. 415).
} 
El tratamiento judicial de los hechos se produce ya, y desde el primer momento, sub specie iuris y en el marco de alguna o algunas hipótesis normativas, que actúan a modo de hilo conductor y circunscriben el desarrollo del proceso en tanto que proceso de adquisición de conocimiento, delimitando al mismo tiempo el espacio de la interpretación. Que es, pues, como escribió Frank, también «interpretación de los hechos» ${ }^{24}$, de los diversos discursos acerca de los mismos que confluyen en el juez.

Esta dimensión de la interpretación ha sido especial y lamentablemente descuidada por los teóricos ${ }^{25}$, como el resultado ciertamente negativo de contribuir, al menos implícitamente, a la identificación de la tarea del intérprete como un simple acto de lectura de textos.

Tal circunstancia ha contribuido, de un lado, a generar la falsa percepción de las cuestiones de hecho como algo previo y exterior al momento propiamente jurídico, dentro del fenómeno global de la aplicación del derecho. Ha alimentado una falsa conciencia sobre los hechos, concebidos como algo dado y significativos por sí mismos, propiciando, correlativamente, la inteligencia de «los juicios de hecho (...) como simples constataciones del 'dato bruto' $»^{26}$. Y ha favorecido, lamentablemente, el olvido de la dimensión esencialmente discursiva de los mismos.

De otra parte, el sensible abandono de la quaestio facti, por considerarla, al menos tácitamente, irrelevante desde el punto de vista de la ciencia del derecho, ha contribuido a abrir una zona de "'discrecionalidad en cuanto a los hechos' o 'soberanía' virtualmente incontrolada e incontrolable, (que) ha sido pasada por alto por la mayoría de los juristas» ${ }^{27}$.

De este modo, mientras la amplia reflexión suscitada a lo largo de los años a propósito del tratamiento de la quaestio iuris ha ido poniendo a disposición de los operadores del derecho con sensibilidad crítica un amplio abanico de recursos teóricos y, sobre todo creando en ellos conciencia de determinadas dificultades, el tratamiento de la quaestio facti aparece objetivamente confiado a la intuición ${ }^{28}$, a la apreciación ingenua del aplicador de aquél, para quien,

${ }^{24}$ J. Frank, Derecho e incertidumbre, trad. de M. Bidegain, revisión de G. R. Carrió, Centro Editor de América Latina, Buenos Aires, 1968, pág. 79.

${ }^{25}$ Un interés, seguramente excepcional entre nosotros, por las cuestiones de hecho en la interpretación, puede verse en F. J. Ezquiaga Ganuzas, op. cit., en especial págs. 34-37.

${ }^{26}$ G. Ubertis, Fatto e valore nel sistema probatorio penale, Giuffrè, Milán. 1979, pág. 25. Más recientemente, esta misma preocupación se hace perceptible en J. Calvo González, El discurso de los hechos, Tecnos, Madrid, 1993.

${ }^{27}$ J. Frank. op. cit., pág. 76.

${ }^{28}$ Este punto de vista tiene frecuente expresión en la jurisprudencia de la Sala 
sintomáticamente, no se prevé ninguna formación específica al respecto ${ }^{29}$.

Incluso, la asimilación del interés por los hechos -y la correlativa llamada de atención acerca de lo que hay de falaz en la certeza del derecho que pretenda obtenerse de espaldas a la dimensión problemática que ellos representan-, a alguna forma de escepticismo jurídico, de subrepticio realismo a la americana, ha contribuido a situar a cualquier manifestación de ese interés bajo sospecha.

Cuando la verdad es que la adecuada comprensión del fenómeno de la aplicación del derecho en toda su complejidad, exigiría, probablemente, situarse más lejos del «formalismo dogmático» que del «conductismo judicial» ${ }^{30}$. Porque, me atrevería a decir, la propia configuración efectiva del ordenamiento, que tantas veces reduce al primero a pura retórica, ofrece amplias posibilidades al segundo en no pocos supuestos ${ }^{31}$, por mucho

esfuerzo que se ponga en la invitación a concebir la función judicial sub specie de fontanería, como en el caso del autor a que antes se hizo referencia.

Segunda del Tribunal Supremo. Así en la sentencia de 12 de febrero de 1993, ponencia de Conde Punipido, donde puede leerse que la convicción que produce la llamada prueba directa «depende de una sene de circunstancias de percepción, experiencia y hasta intuición, que no son expresables a través de una motivación».

${ }^{29}$ Como ha señalado M. Atienza, «la teoría de la argumentación jurídica dominante se centra en las cuestiones -los casos difíciles- relativas a la interpretación del Derecho... [si bien] la mayor parte de los problemas sobre los que tienen que conocer y decidir tanto los tribunales como los órganos no jurisdiccionales de la Administración son más bien problemas concernientes a los hechos, de manera que los argumentos que tienen lugar con ocasión de los mismos caen fuera del campo de estudio de las teorías usuales de la argumentación jurídica» (Las razones del Derecho. Teorías de la argumentación jurídica, Centro de Estudios Constitucionales. Madrid, 1991, pág. 20).

${ }^{30}$ Tomo la expresión de L. Hierro, El realismo jurídico escandinavo, Fernando Torres, Valencia, 1981, pág. 98.

${ }^{31}$ Un caso paradigmático de la escasa capacidad descriptiva del punto de vista del formalismo dogmático y de la predisposición del propio sistema jurídico, en no pocas ocasiones, a ser explicado en clave «conductista» lo ofrece hoy el tratamiento del aborto en el Código Penal, a partir de la despenalización parcial introducida por la Ley orgánica 9/1985, de 5 de junio, a través del art. 417 bis. En efecto, el delito de aborto ha llegado a dejar de existir salvo en la práctica de algunos -muy pocos- jueces y fiscales, de significativa caracterización ideológica y de muy concreta localización territorial, por otra parte. Y todo, con ostensible complacencia de la mayoría parlamentaria responsable del actual tratamiento legislativo del asunto, que, como es bien notorio, ve, paradójicamente, con complacencia la inaplicación de su ley.

Otro supuesto que puede servir para ilustrar lo que se afirma es la interpretación que la Sala Segunda del Tribunal Supremo, hace de la relación entre el art. 344 del Código Penal y el art. 1.3.1 a de la Ley orgánica 7/1982, de 13 de julio, sobre contrabando. Así, mientras en la sentencia de 12 de junio de 1990 (ponente García Ancos), se rechaza «(por obvio) que tal introducción -de droga en España- pueda constituir ningún atentado contra el erario público, al tratarse de productos que se hallan fuera 
En consecuencia, resulta inevitable descartar, incluso como posibilidad, la existencia empírica, dentro de la «interpretación operativa», de algún momento autónomo de prejurídica aprehensión de datos puramente fácticos, en una perspectiva ontológico-metafísica.

Por otro lado, debe asimismo rechazarse una forma de entender el viejo aforismo procesal da mihi factum... como significativo de cierta pasividad del intérprete-operador, del juez del enjuiciamiento, incluso en el proceso civil. Porque, si es cierto que, tanto en éste como en el penal regido por el principio acusatorio, el juez está estatutariamente obligado a abstenerse de todo protagonismo e iniciativa en la obtención del material probatorio, no lo es menos que la aportación de parte de esos elementos de convicción es sólo un presupuesto de la conformación del supuesto de hecho, que corresponde a aquél en el ejercicio de su libre convicción, racionalmente ejercida y fundada.

Efectivamente, el juez recibe testimonios, examina documentos, analiza datos, que le son presentados en forma contradictoria e interesada. Sobre ellos debe realizar una cuidadosa labor de valoración crítica, desechando no sólo los que no ofrezcan garantías de veracidad, sino incluso aquellos que, con independencia de su eventual valor informativo, no hubieran sido obtenidos en el respeto de determinadas reglas procesales del juego, integrantes de la disciplina constitucional del proceso. Así resulta que la dimensión jurídico-sustantiva implícita en el tratamiento de la cuestión de hecho que viene dada ya en un primer momento por la concurrencia de una hipótesis normativa como hipótesis de trabajo del intérprete operativo, aparece además reforzada por la predisposición de un marco formal, imperativo, al que ha de ajustarse el proceso como proceso de adqui-

de comercio»; en la de 25 de junio de 1990 (ponente Sierra Gil de la Cuesta), se lee que «hay que destacar que la tenencia de droga con propósito de tráfico e introducida clandestinamente en territorio nacional, supone la existencia de dos bienes jurídicos atacados por dicha conducta delictiva de doble vertiente, como es, por un lado, el bien jurídico de la salud pública, y por otro, el que acomete a la hacienda pública...».

Con la curiosa particularidad de que una y otra sentencia aparecen fichadas con números correlativos (1185 y 1186) en el repertorio jurisprudencial Colex, de ese año.

Este dato evidencia un problema de falta de coordinación en la formación de criterio del alto tribunal, es cierto. Pero también lo es que la situación está determinada por una previa contradicción entre la línea de política criminal, con expresión en los preceptos tenidos en cuenta, Y ciertas reglas dogmáticas -también con reflejo legal- que constituyen el sustrato teórico de nuestro orden punitivo.

Son simplemente dos ejemplos de los muchos que cabría citar, y que evocan problemas jurídico-prácticos que no resuelve sin más ninguna inteligencia sistémica del orden jurídico que haga abstracción de su forma de ser real. 
sición de conocimiento, si se quiere que éste resulte jurídicamente relevante. Y ello sin salir de lo que convencionalmente se considera el campo de la quaestio facti.

\section{La interpretación, entre Code y «descodificación»}

Ocurre, por otra parte, que el punto de vista del formalismo dogmático, si es desafortunado al discurrir sobre el papel del intérprete, carece también de la aptitud descriptiva del ser real de la ley que le atribuyen sus defensores. Y, por consiguiente, también de eficacia explicativa acerca del modo de producirse efectivamente la actividad del intérprete. De cualquier intérprete, pero en particular del que aquí más nos interesa.

Esto que puede afirmarse, desde luego, aunque se tome como punto de referencia el del Code en cuanto modelo de legalidad arquetípico y el más próximo cronológica y teóricamente a aquellas posiciones, resulta aun más evidente cuando se consideran las transformaciones experimentadas por la forma ley en momentos más próximos al nuestro y en el momento actual ${ }^{32}$.

Como se sabe, el ritmo frenético de producción de leyes se ha visto acompañado por importantes cambios en la significación e incluso en la morfología de éstas, que han tenido como primera consecuencia la de acentuar el carácter asistemático e internamente conflictual del ordenamiento, con incidencia inevitable en el ámbito de la interpretación. Así, al fenómeno «descodificador», denunciado tan gráficamente por Irti en el campo del derecho privado, tiene una primera y más aparente manifestación cuantitativa, pero se proyecta también sobre la propia calidad discursiva del texto: «las leyes se multiplican no solamente en el número, sino en las modalidades expresivas y sintácticas, al plegarse cada una al léxico particular o a la simple jerga de la materia regulada. Se aleja cada vez más el mito de un lenguaje matematizador, que se desarrolle sobre la base de significados convencionalmente preestablecidos y según precisas reglas de transformación. Los lenguajes de las leyes, múltiples y discordantes, prolijos y ambiguos, declamatorios y programáticos, hacen ya imposible un lenguaje unitario del derecho civil, del que el intérprete pueda extraer criterios constantes y unívocos de lectura. La variedad expresiva, que era propia de los negocios privados, se ha transferido a las leyes.... $\rangle^{33}$.

${ }^{32}$ Para una aproximación general a esta cuestión, cfr. P. Barcellona, I soggetti e le norme, Giuffrè, Milán, 1984, en especial págs. 141 y ss. Más recientemente, S. Rodotà, Repertorio di fine secolo, Laterza, Roma-Bari, 1992, págs. 150-169.

${ }^{33}$ N. Irti, L'età della decodificazione, Giuffrè, Milán, 1979, pág. 17. 
El fenómeno está íntimamente ligado a la cada vez más frecuente degradación de la actividad normativa a actividad de gobierno ${ }^{34}$, que tiene su concreción más significativa en las, tan expresivamente, denominadas leggine por la doctrina italiana, a través de las cuales el parlamento se limita «a ejercer una función administrativa» ${ }^{35}$.

La situación de la que estos datos son elementos integrantes, a la vez que sugiere un cambio no desdeñable en el papel desempeñado por el legislador, conlleva también repercusiones en la actual significación de la función judicial. De una parte, por la clara interferencia en el ámbito constitucionalmente acotado para la jurisdicción que implica ese modo de legislar ${ }^{36}$. De otra, porque, simultánea y paradójicamente, el mismo carácter proteiforme y progresivamente asistemático ${ }^{37}$ del universo normativo aplicable amplía el espacio abierto a la discrecionalidad judicial, el abanico de las opciones jurisprudenciales posibles y, por consiguiente, el protagonismo del juez, cuyo «concurso activo» se requiere, como ha escrito Senese, para «la definición de la regla que le vincula y debe aplicar» ${ }^{38}$. El fenómeno descodificador $r^{39}$ tiene entre nosotros una reciente manifestación en la Ley

${ }^{34}$ P. Barcellona, op. cit., pág. 146.

${ }^{35}$ Así S. Rodotà, que señala como «consecuencia de este estado de cosas sustancialmente dos: la dificultad de obtener una adhesión «general» a una ley así elaborada; y un cambio en el papel del juez llamado a aplicarla, que a los ojos de la colectividad no aparece como un tercero imparcial, sino como el último eslabón de una cadena política» (op. cit., pág. 154).

${ }^{36}$ Cfr. sobre el particular: S. Muñoz Machado, La reserva de jurisdicción, La Ley, Madrid, 1989, en especial págs. 44 y ss.

${ }^{37}$ De este aspecto de los modernos ordenamientos se ha ocupado V. Italia, en La Fabbrica delle leggi, Giuffrè, Milán, 1990, que hace referencia, entre otras vertientes del fenómeno, a la constituida por el juego de las leyes especiales (cfr. págs. 57 y ss.).

${ }^{38}$ S. Senese, voz «Giudice (nozione e diritto constitucionale)», Digesto, Utet, Turín, 1991, 4a . ed., vol. VII, pág. 42, de la separata, por donde se cita.

Señala el autor cómo esa ley, a cuya definición debe concurrir el juez «no se presenta como un dato textual inmóvil y fijo puesto por una única autoridad, sino que es más bien una combinación de ley ordinaria y norma constitucional que puede invalidarla o, de cualquier modo, ponerla en tensión, de leyes y tratados internacionales, a las que hoy se añade, y en medida creciente, la normativa comunitaria» ivi, págs. 41-41.

${ }^{39}$ En contra de lo que el propio término pudiera sugerir, la descodificación no se produce sólo por la dispersión en una pluralidad de textos legales del tratamiento de materias que antes lo tenían exclusivamente en uno: el código correspondiente. Hay también descodificación cuando, mediante reformas parciales, se rompe la unidad de principios inspiradores o la organicidad de una determinada regulación, bajo la apariencia de formal conservación como vigente del texto matriz. Un caso paradigmático es sin duda el de la Ley de Enjuiciamiento Criminal, en vigor desde 1882, a pesar de que, en la actualidad, el proceso-tipo que allí se establece ha pasado a tener una significación marginal en términos estadísticos. Y también a pesar de que en ella coexisten modelos procesales que responden en su inspiración a criterios con frecuencia antitéticos. (Me he ocupado de esto en «Cien años después: lo que queda de 
orgánica 1/1992, de 21 de febrero, sobre Protección de la Seguridad Ciudadana, más conocida como ley Corcuera. Manifestación de extraordinario valor emblemático y de singular relevancia negativa, porque incide en el terreno especialmente sensible de los derechos fundamentales. Esta ley, con la sedicente pretensión de salir al paso de coyunturales fenómenos productores de «inseguridad ciudadana» mediante lo que, supuestamente, sería sólo un coherente desarrollo del dictado constitucional, supuso una verdadera contrarreforma penal-procesal y del derecho administrativo sancionador, que rompe en aspectos significativos con el precedente modo de entender algunos elementos relevantes del sistema de principios que la Constitución consagra en materia de derecho punitivo y en lo que se refiere a las relaciones juez/policía.

Por eso, renunciando -lo que ciertamente no es fácil- a consideraciones más precisas sobre los contenidos de ese malhadado instrumento legal ${ }^{40}$, es útil referirse a él como momento de verificación de lo que se viene diciendo acerca de las transformaciones operadas en el orden normativo. Y precisamente en aquel sector del mismo, el derecho punitivo en sentido amplio, que ha sido tradicionalmente el objeto por antonomasia de las preocupaciones dogmáticas, de los más caracterizados intentos de reducción del campo abierto a la disponibilidad del intérprete, con fines de garantía.

Pues bien, el art. 21 de la ley Corcuera se separa sensiblemente del tratamiento -inspirado en el principio del hecho- que la libertad personal recibe en el art. 17 de la Constitución Española y contradice el paradigma indiciario acogido en la ley-marco en cuestión de intervenciones coactivas sobre las personas, que es la de Enjuiciamiento Criminal. Y, al hacerlo, acentúa la quiebra de la unidad de principios inspiradores del orden penal-procesal. Esto ilustra acerca de lo que se ha venido considerando una, o quizá la más significativa, de las propiedades de la llamada legislación excepcional, pero que, como ha puesto de relieve recientemente Ferrajoli ${ }^{41}$, representa sobre todo -en versión macroscópica, si se quiere- uno de los rasgos constitutivos del orden jurídico del estado de derecho y, en esa calidad, tiene extraordinaria relevancia para la labor del jurista-intérprete.

la Ley de Enjuiciamiento Criminal», ahora en Justicia/conflicto, Tecnos 1988, págs. 145 y ss.)

${ }^{40}$ Remito al respecto a mi «Viaje a la prehistoria de las garantías: la «modernización» de la ley Corcuera», en Jueces para la Democracia. Información y debate, 13, 2/1991, pág. 3 y ss. Cfr. asimismo E. Berlanga Ribelles, «Régimen sancionador en la ley Corcuera», en la misma revista, $\mathrm{n}^{\circ}$. $14,3 / 1991$, pág. 18 y ss.

${ }^{41}$ L. Ferrajoli, Diritto e ragione. Teoria del garantismo penal, Laterza, Roma-Bari, $1^{\mathrm{a}}$. ed., 1989, pág. 348 y ss. Edición castellana en curso de publicación por Editorial Trotta, Madrid. 
Señala este autor que la positivación de los derechos fundamentales de la persona en los modernos ordenamientos constitucionales, ha transformado, en buena medida, la vieja distancia entre el ser y el deber ser ideal del derecho, expresada antes en la dicotomía ley positiva/ley natural, en un contraste entre ser y deber ser en el derecho, que se presenta ahora como una incoherencia o antinomia interna. Como un desfase entre sus diversos niveles normativos. Porque, en efecto, es bien conocido e incluso tópico, que las exigentes formulaciones que con carácter de derecho positivo se contienen en las constituciones de nuestros estados de derecho, distan mucho de verse plasmadas con el mismo rigor en las disposiciones de inferior rango, por no hablar ya de las prácticas de los sujetos institucionales.

Semejante evidencia justifica, a juicio de Ferrajoli, la acuñación de un nuevo concepto, sustancial, de validez de las normas, que concurre sólo cuando éstas, además de no haber sido producidas de forma regular -es decir, de hallarse formalmente vigentes-, responden en sus contenidos a las exigencias de principio proclamadas en la Constitución. De donde la habitual falta de traducción fiel de tales exigencias en la legalidad ordinaria debe ser tomada como una constante estructural del estado de derecho, que resulta así connotado por una permanente tasa de ilegitimidad jurídica, derivada de la falta de respeto a las reglas que el mismo se ha dado. La toma de conciencia de esta situación comporta para el intérprete, vinculado por el principio de jerarquía normativa, y en particular para el juez, un inevitable elemento de tensión y un nuevo factor de dificultad, puesto que claramente introduce un serio coeficiente de distorsión en el ámbito de la legalidad.

\section{Levantar el velo}

Los datos esquemáticamente sugeridos en lo que precede llevan de forma inmediata a un resultado: tener que rechazar la imagen del ordenamiento y de la tarea interpretativa que sugiere el formalista dogmático. Y no por ingenuamente irreal, sino, antes bien, por activamente encubridora de aspectos sustantivos de la realidad de la experiencia jurídica y del inevitable condicionamiento que de éstos se deriva para el actuar del juez.

Frente a aquella propuesta, que gusta presentarse enmarcada por un halo de neutralidad y cientifismo, que difícilmente puede ocultar, sin embargo, su ostensible falta de rigor y su organicidad a una concreta política del derecho con tendencia a autovalorarse como la única constitucionalmente posible, se impone la afirmación insistente de determinados rasgos de nuestra realidad jurídica. Unos atinentes al universo normativo, otros característicos de la actividad de sus 
operadores; y todos ellos condicionantes -como se ha dicho- de la naturaleza y la calidad de las prácticas en que se concreta la aplicación del derecho, la judicial especialmente.

De entre esos rasgos me parece necesario destacar fundamentalmente los siguientes:

1. La expresión «estado de derecho» hace referencia a un modelo límite, caracterizado en su funcionamiento por un permanente grado de insatisfacción de las exigencias de principio normativamente asumidas como criterio inspirador y regulador de su propia actividad. De ahí deriva lo que Ferrajoli ha descrito como «la aporía de la irreductible ilegitimidad jurídica de los poderes públicos en el estado de derecho» ${ }^{42}$.

2. Esta dimensión estructural de íntima contradictoriedad se ha visto acentuada, de una parte, con la incorporación a los catálogos constitucionales de los llamados «derechos sociales», de imposible actuación y accionabilidad por sus hipotéticos titulares, como tales derechos, y así condenados, no obstante el rango normativo de su formulación, a la inexistencia práctica y jurídica. Y, de otra, porque en los estados -«sociales» o no- de derecho se ha acentuado extraordinariamente la desviación del modelo constitucional, en lo que se refiere a los modos de operar y de relacionarse recíprocamente el legislativo y el ejecutivo. Todo ello con inevitable repercusión en el estatuto efectivo del poder judicial.

3. E1 tenor de algunas intervenciones de cerrado sabor formalista, como aquella de la que se ha dejado constancia, hace necesario reiterar la obviedad de que el legislador real no es desde luego el que presuponen los planteamientos del formalismo dogmático. Y no lo es en varios sentidos: porque no ostenta el monopolio de la legitimidad en el complejo proceso de producción-realización del derecho; porque su intervención no cierra el ordenamiento al juego de las influencias extrasistémicas en los distintos momentos de su aplicación ${ }^{43} \mathrm{y}$, en consecuencia, tampoco excluye toda otra actividad creadora de derecho ${ }^{44}$. También en el sentido de que, con frecuencia, los actos del legislativo presentan una dimensión política colateral o sobreañadida que nada o poco tiene que ver con la que corresponde a la fisiología

\footnotetext{
${ }^{42}$ L. Ferrajoli, Diritto e ragione cit., pág. 907.

${ }^{43}$ Como gráficamente expresara Calamandrei, «si el jurista va en busca de la ratio legis, esto quiere decir remontar las corrientes políticas que han originado la ley» («La crisis de la justicia», en La crisis del derecho, de varios autores, trad. de M. Cheret, EJEA, Buenos Aires, pág. 320).

${ }^{44}$ A este respecto, como ha señalado Capelletti, cabe decir que, «desde el punto de vista sustancial, la creatividad del legislador puede ser en suma cuantitativamente, pero no cualitativamente diversa de la del juez» (Giudici legislatori?, Giuffrè, Milán, 1984, pág. 16.).
} 
del modelo, que, por el contrario, resulta defraudada. Me refiero a los supuestos en que el acto formal de legislar -por el juego de las relaciones entre partidos, en función de coyunturales intereses, o por pura inhibición difícilmente justificable, sobre todo en algunos temas- se resuelve en una verdadera y propia elusión de la responsabilidad de dar el adecuado tratamiento normativo a alguna cuestión conflictiva, que así se desplaza en su integridad problemática al juez ${ }^{45}$.

4. También parece conveniente reiterar la inadecuación de la categoría sistema para referirse al conjunto de reglas jurídico positivas que disciplinan una determinada realidad. $\mathrm{O}$, caso de no renunciarse a su empleo, habría que tomar en consideración que es la aportación de la jurisdicción y de la doctrina la que contribuye a dar al término lo que pudiera tener de proximidad descriptiva al dato empírico. Como escribió Tarello, «el carácter de ser sistema no es un carácter de conjunto de las normas de un derecho, sino antes bien un carácter del modo de mirar adoptado por quien examina el conjunto de las normas de un derecho. No es que el derecho en sí constituya un sistema, sino que el derecho en cuanto mirado como conjunto de normas interrelacionadas (por ejemplo, por la unidad de fuentes, de derivación material o formal, de proyección institucional, de usuarios o grupos de usuarios, de fin analítico) aparece como sistema (en uno o más de los significados mencionados) $\rangle^{46}$.

Por eso, la afirmación de que la clausura del ordenamiento a la

\footnotetext{
${ }^{45}$ Pocos ejemplos tan elocuentes como los representados por las intervenciones corporales y las interceptaciones telefónicas.

Las primeras, cuya afectación a derechos fundamentales como la integridad física, la libertad y la intimidad personal (arts. $15,17,1 .^{\circ}$ y $18.1^{\circ}$ de la Constitución) es poco discutible, y cuya práctica, sobre todo en alguna de sus modalidades como el cacheo con desnudo integral, goza de notable amplitud (de las aduanas a las comisarías, pasando por los centros penitenciarios), a dieciséis años de 1978 pertenecen en el más absoluto vacío legal. Mal cubierto en el caso de los análisis de sangre, para verificación del índice de alcohol en materia de tráfico, por una disposición sin rango de ley orgánica. De este modo, tales medidas sumamente agresivas para aquellos derechos fundamentales, se hallan abiertas a una utilización que difícilmente puede dejar de ser arbitraria, cuando faltan los mínimos referentes normativos.

Las segundas no conocieron hasta 1988 otra regulación que la supuestamente implícita en el art. 18. $3^{\circ}$. de la Constitución, que sólo preveía la derogación del derecho al secreto de las comunicaciones en virtud de resolución judicial. Pues bien, la Ley Orgánica 4 de ese año, de 25 de mayo, modificando el art. 579 de la Ley de Enjuiciamiento Criminal, desarrolló el precepto constitucional en términos de extraordinaria precariedad e insuficiencia, y que producen más perplejidades que seguridad en la práctica, puesto que omiten los aspectos esenciales del uso con garantías del que se ha convertido en uno de los medios más extendidos -y más agresivos- de la investigación criminal.

${ }^{46}$ S. Castignone, R. Guastini, G. Tarello, Introduzione teorica allo studio del diritto. Lezioni, ECIG, Génova, 1979, pág. 94.
} 
influencia de elementos extrasistemáticos es un dato constitutivo del mismo, lejos de describir algún fenómeno real más bien prescribe un modo de ser prácticamente irrealizado, por irrealizable, y oculta las inevitables insuficiencias ordenadoras de cualquier orden jurídico. De ahí, precisamente, la necesidad de un permanente esfuerzo integrador; por lo general encomendado a la magistratura ${ }^{47}$. Labor integradora que en el discurso formalista se niega o se oculta tras de la ficción consistente en «aparentar que los criterios de decisión siguen siendo intrasistémicos» ${ }^{48}$.

5. La ambigüedad de los términos y vaguedad de los conceptos, que se registran en el lenguaje natural son, asimismo, predicables, como bien se sabe, del lenguaje jurídico, que no es sino una manifestación tecnificada de aquél ${ }^{49}$. Una y otra, ambigüedad y vaguedad, pueden verse acentuadas hasta límites insospechados por razones puramente técnicas, de mala técnica legislativa; ésta, a veces, simple instrumento de una opción política expresiva de la voluntad de dejar un género de supuestos en una situación de indefinición normativa calculada.

6. A los aspectos de imprecisión y ambigüedad que connotan las disposiciones jurídicas ya en el plano puramente discursivo, se unen las discontinuidades e incluso contradicciones constatables en el ámbito de los principios informadores y de los contenidos normativos, que justifican, como hemos visto, la denuncia de una ineliminable tasa de «ilegitimidad jurídica» como dato constitutivo del orden legal del Estado de derecho.

7. Las circunstancias a que acaba de aludirse se proyectan en su conjunto sobre la actividad del juez coadyuvando a hacerla, en alguna medida, incierta. Esta incertidumbre y la correlativa imprevisión acerca del comportamiento del juez que necesariamente lleva consigo, confieren a la actuación de éste una consistente dimensión política. Como ha recordado Guarnieri, «el juez puede elegir entre alternativas

${ }^{47}$ A este respecto J. R. Capella ha escrito: «La intervención de la autoridad jurídico-política, aunque no elimina las deficiencias (lagunosidad, contradictoriedad, vaguedad o ambigüedad) que se oponen a la calculabilidad del derecho y a su pretensión sistemática, realiza en cambio la función de alterar el derecho existente integrándolo con normas a él ajenas hasta el momento de esa intervención». (Sobre el discurso jurídico. La teoría general de las normas, Barcelona, Facultad de derecho, texto fotocopiado, pág. 58).

${ }^{48}$ J. A. Estévez Araujo, «La Jurisdicción: definición y criterios de legitimidad», en Jueces para la Democracia. Información y Debate, no. 9, abril, 1990, pág. 19.

${ }^{49}$ Cfr. G. R. Carrió, op. cit., págs. 28 y ss.; J, R. Capella, El derecho como lenguaje, Ariel, Barcelona, 1968, págs. 246 y ss. También A. Gómez y O. M. Bruera, Análisis del lenguaje jurídico, Editorial de Belgrano, Buenos Aires, 1991, págs. 79 y ss. 
sobre las que existe incertidumbre» ${ }^{50}$; y el espacio que así se abre a la decisión relativamente autónoma implica «un nuevo poder» ${ }^{51}$.

Más recientemente, Ferrajoli ha puesto de relieve que «la politicidad de la actividad judicial no es el fruto de una opción ideológica o deontológica, sino un dato de hecho, ligado a los defectos de garantías y a las imperfecciones estructurales que están presentes en diversas formas en todos los ordenamientos penales positivos $\rangle^{52}$.

8. Junto a esa tasa inevitable de impregnación política, coesencial o inmanente al modo de operar judicial, se ha producido la activación de otra fuente de politización de la función jurisdiccional, difícil de imaginar hasta hace bien poco.

La cuestión tiene que ver con la progresiva extensión de la esfera de la acción pública y con un preocupante deterioro de la misma, que hace que el Estado aparezca, de una u otra forma, cada vez con más frecuencia, como justificable. Y no sólo ante la jurisdicción contencioso-administrativa, sino ahora también ante la penal. Carlos de Cabo había descrito, tiempo atrás, alguno de los aspectos de este fenómeno como «judicialización del conflicto socio-político ${ }^{53}$. Hoy menudean las alusiones a la judicialización (en la vertiente penal) como una incidencia patológica. Ocurre, sin embargo, que la patología -por la degradación posiblemente criminal de un porcentaje sorprendente de conductas de operadores públicos- precede a la intervención -necesaria- del juez.

No han faltado interpretaciones demagógicas y reductivas del

${ }^{50}$ C. Guarnieri, L’indipendenza della magistratura, Cedam, Padua, 1981, pág. 47.

Al hablar de incertidumbre no se piensa sólo en casos-límite, supuestos de libro, de escasa incidencia práctica, sino en muchos que afloran en la práctica cotidiana de cualquier juez. Así, por ejemplo, los que se presentan con ocasión de la aplicación del último párrafo del art. 501 del Código Penal, cuando se refiere al uso de «medios peligrosos», como criterio de agravación específica de la pena. O del art. 344 bis a) $3^{\circ}$. del mismo texto legal, cuando hace uso de la expresión «notoria importancia», relativa a la cantidad de la droga aprehendida. En ambos casos se trata de una calificación con importantes consecuencias en el orden de la pena, y en ellos el criterio de demarcación se cifra en grados de peligrosidad o en gramos de sustancia, en principio de libre apreciación.

${ }^{51}$ C. Guarnieri, op. cit., pág. 57.

${ }^{52}$ L. Ferrajoli, Diritto e ragione, cit. p...

${ }^{53}$ C. de Cabo Martín, La crisis del estado social, PPU, Barcelona, 1986, pág. 75. Ahora suele hablarse de una -se sugiere que abusiva- «judicialización» de la política. Se habla menos de que ésta tiene que ver muchas veces con una previa degradación criminal de la misma y con un desprejuiciado recurso al juzgado como instrumento de lucha política, al que generalmente no renuncia ningún partido. (Cfr. sobre estas cuestiones mi trabajo: «La corrupción en el banquillo. Jurisdicción penal y crisis del Estado de derecho», en Claves de razón práctica, nº . 40, marzo de 1994, págs. 2 y ss.). 
fenómeno, que ha querido atribuirse a una especie de súbita explosión de incontrolado afán de protagonismo en los medios de la magistratura. Sin embargo, como ha hecho notar Rodotà, refiriéndose al caso italiano, ciertamente paradigmático en la materia, «todos los indicadores cuantitativos disponibles señalan, por el contrario, que es la sociedad la que exige una cuota creciente de respuesta judicial»; y no puede decirse que la de los jueces en estos supuestos sea «una actividad impropia o incluso, ilegítima, porque, en la inmensa mayoría de los casos, se ha tratado de atribuir relevancia a derechos, intereses, necesidades, sujetos, que ya habían asumido relevancia en el cuadro constitucional o, incluso, habían obtenido un reconocimiento formal por parte del legislador» ${ }^{54}$. Y en muchos otros supuestos, no se ha hecho más que aplicar previsiones contenidas en el Código Penal, de valor normativo, al menos en principio, erga omnes ${ }^{55}$, a conductas típicas.

Resulta así que el juez, que, en general, nunca había podido elegir dejar de ser -en alguna medida- político, en la situación en curso, tampoco ha tenido la oportunidad de optar autónomamente por ser más político. Simplemente ha visto crecer la incisividad y frecuencia de sus intervenciones en espacios que habían permanecido generalmente inmunes a ellas, y acentuarse la densidad política de las mismas, por la dimensión pública de los sujetos tocados ahora por el ius puniendi. No resulta extraño que tales acciones susciten un notable malestar, por la carga de deslegitimación que conllevan para los afectados y por lo difícilmente objetables que resultan en el plano de la legalidad. Y que, asimismo, rompan algunos esquemas consolidados.

Pero lo que no puede aceptarse son los intentos de presentación del asunto como una suerte de toma por los jueces de algún poder atípico. Porque los jueces como sujeto colectivo titular de la jurisdicción no existen, ya que la proyección de la actividad jurisdiccional, por su propia naturaleza -tratamiento individualizado de supuestos concretos ya producidos- es solamente intersticial ${ }^{56}$, ocasional, asistemática, y se limita a ocupar, caso por caso, y respondiendo a una demanda externa, los espacios previamente abiertos por la actividad normativa. En cualquier caso, esa nueva forma de presencia judicial en un campo en el que la misma era prácticamente desconocida,

${ }^{54}$ S. Rodotà, $o p$,. cit., págs. 171 y 174.

${ }^{55}$ Un excelente tratamiento de estos asuntos en la perspectiva de la experiencia italiana, puede encontrarse en E. Bruti Liberati, «La magistratura e i fatti di corruzione politica», en Questione Giustizia, n. ${ }^{\circ} 3-4 / 1992$, págs. 489 y ss.

${ }^{56}$ Cfr. Guarnieri, op. cit., pág. 42. También M. R. Ferrarese, L'instituzione dificile. La Magistratura tra professione e sistema politico, Edizione Scientifiche Italiane, Nápoles, 1984, pág. 124. 
expresa una potencialidad implícita en el diseño del poder judicial en el estado constitucional de derecho, como articulación institucional al servicio de un principio, el de legalidad, que, sobre todo en su vertiente penal y en presencia de lesiones a ciertos bienes jurídicos colectivos esenciales, no admite restricciones, y menos por razón de los sujetos.

9. No parece ya fácil, en este contexto -y menos aún a la vista de ciertos hechos-, presentar el momento interpretativo y, sobre todo, la interpretación judicial del derecho como el simple acto de lectura de un texto diáfano en su significación y desproblematizado, por parte de un operador-terminal-pasivo de un sistema al que se hallase conectado poco menos que electrónicamente. Por el contrario, en el acto de aplicación del derecho el dato legal lleva consigo o está abierto a otros extralegales, que invariablemente le acompañan; mientras que el juez pone en aquella tarea bastante más que el simple accionamiento de la llave de paso en un sistema de cañerías.

Esto, en el desarrollo de la que cabría llamar administración ordinaria de justicia, porque en aquella otra clase de supuestos recientes, ya no sabría decir si extraordinarios, a que he aludido, los factores de complejidad y el espesor directamente político del actuar judicial conocen un desarrollo verdaderamente macroscópico. Cierto que no hay salidas judiciales para las crisis políticas. Pero está por ver si resulta constitucionalmente posible eludir el tratamiento judicial de las cuestiones que legalmente lo demanden y cuáles serían las consecuencias para el sistema democrático, de no hacerlo.

10. Hay situaciones, como la generada en España por la transición democrática que, además, en todo caso, añaden otro nuevo ingrediente de complejidad a los ya señalados -a los señalados como normales- en la materia que nos ocupa. Me refiero al identificado por Ferrarese en la emergencia de una Constitución con carácter de norma positiva de aplicación directa, es decir dotada de valor jurídico-formal, y, al mismo tiempo, abierta de manera explícita a valores (civiles, políticos, éticos) ${ }^{57}$. De ello se deriva la consecuencia de

${ }^{57}$ G. Zabrebelsky ha señalado «que si se tienen en cuenta algunos datos de hecho: que hoy los principios que contienen valores de justicia se han convertido en derecho positivo integrado en la constitución; que, en consecuencia, la apelación a la justicia junto a o contra las reglas de la ley, ya no puede seguir viéndose como un gesto subversivo o destructivo del derecho (a diferencia de lo que sucedía en la época del positivismo jurídico), sino que es una eventualidad prevista y admitida; que tales principios consisten esencialmente en «nociones de contenido variable» y por tanto cumplen una función esencialmente dinámica, si se considera todo esto, entonces se comprenderá que, con ello, se ha injertado en el propio ordenamiento una fuerza permanentemente orientada al cambio». (Il diritto mite, Einaudi, Turín, 1992, págs. 201-202. [Trad. cast. de M. Gascón Abellán, en preparación por Editorial Trotta, Madrid]). 
que «cuanto más se aproxima la esfera operativa del juez al terreno de la constitucionalidad, tanto mayores resultan las implicaciones del mismo en materia de legitimidad ${ }^{58}$. Y, en consecuencia, tanto más potencialmente conflictivas las relaciones con las instancias concernidas.

11. Parece necesario reiterar, por la falta de tratamiento que, en general, padece la quaestio facti, que es en la fijación de la misma donde se concentra, quizá, el mayor grado de discrecionalidad que cabe en la aplicación judicial del derecho. Y también llamar de nuevo la atención acerca del escaso interés que este aspecto, nuclear, del asunto ha suscitado en el jurista formalista y, probablemente, incluso no-formalista.

Quizá porque la cuestión de la fijación de los hechos, que tiene su sede más sensible y más caracterizada en el campo del derecho punitivo, ha estado tradicionalmente abandonada a la discrecionalidad policial. Discrecionalidad confortada por una actitud judicial -ésta sí pasiva y formal- de complaciente inhibición legitimadora de pautas institucionales con muchísima frecuencia infralegales. Por ello, no tiene nada de particular que la taxonomía jurídica se haya detenido en los límites de lo que sería ya el ámbito de otra disciplina o bien un puro dato de facto, cabe incluso que extra-sistémico, y, en cuanto tal, irrelevante para el jurista.

\section{La difícil certeza posible}

Reformulada aquí la pregunta que encabeza este texto, creo que la respuesta se encuentra ya dada. La ley, aun si concebida sub specie del paradigmático tipo ideal representado por el Code, es claro que no dejaría nunca de estar abierta a una cierta diversidad de tomas de posición en el momento aplicativo. Incluso en el caso de que un «hercúleo» autor del texto, cuadrando el círculo, hubiera logrado expulsar del mismo cualquier sombra de vaguedad, toda ambigüedad posible, siempre quedaría pendiente la tarea de producir en serie el número de intérpretes-clónicos, programados en una única clave de lectura, que fuera necesario para accionar, con uniformi-

Manuel Atienza ha puesto recientemente de manifiesto, entre nosotros, de forma bien gráfica cómo puede traducirse este rasgo del ordenamiento constitucional en la práctica de los tribunales en presencia de un «caso difícil» interferido por fuertes exigencias de carácter práctico-político. Vid. de este autor: Tras la justicia. Una introducción al Derecho al razonamiento jurídico, Ariel, Barcelona, 1993, en particular el capítulo cuarto, «Cuestiones de vida o muerte. Sobre el alcance del derecho a la vida», págs. 88 y ss.

${ }^{58}$ M. R. Ferrarese, op. cit., pág. 69-70. 
dad de cadena de montaje, todas las «llaves» de la «red» (dicho sea en jerga de fontanería sistémica).

Cuando el orden jurídico, por el contrario, se encuentra tan alejado de aquel modelo como lo está actualmente el que forma parte de nuestra realidad, parece que cualquier intento serio de comprensión demanda un tipo de aproximación bien distinto.

En esa línea apunta lo que se ha venido exponiendo, que pone de manifiesto la inviabilidad de un tipo de certeza, la del positivismo legalista, que en opinión de uno de sus más caracterizados exponentes sólo sería posible cuando «domine soberana... una voluntad constante, coherente consigo misma, objetivada y objetivamente válida: es decir, la voluntad de la ley» ${ }^{59}$. «La certeza del derecho como certeza legal, absolutamente irrealizable en el estado contemporáneo» $\left(\right.$ Corsale $\left.{ }^{60}\right)$.

Ahora bien, la denuncia de la condición no simplemente ideal, sino ideológica de ese tipo de certeza, no implica la exclusión de cualquier otra modalidad de certeza como posible. Y, menos aún, que se ponga en duda la importancia que un razonable grado de previsible regularidad de las respuestas del ordenamiento, en particular a través de las resoluciones judiciales, tiene para el desarrollo de la vida social y política de cualquier comunidad organizada.

Ocurre, sin embargo, que los datos de que se dispone acerca del modo de ser del orden jurídico y de los factores de diversa índole que inciden en su aplicación, llevan necesariamente a pensar en el valor de certeza, no como una propiedad metafísica que fluyera unilateralmente y sin más del texto legal, sino como la resultante esperable -dentro de algunos límites- del juego interactivo de toda una serie de factores. Una serie compleja de factores de cierta heterogeneidad, de la que algunos relativamente son controlables por el conjunto de los operadores que intervienen en los diversos momentos del proceso de producción y aplicación de la ley. Y, también, al menos en alguna medida, susceptibles del principio de control que implica el conocimiento y la posibilidad de valoración y crítica pública ex post por los destinatarios del conjunto de acciones institucionales de que se trata. Otros, tienen que ver con transformaciones en curso que afectan en profundidad a la actual forma de estado constitucional de derecho, a las relaciones internas entre sus diversas instancias, y a las de éstas con la sociedad, y cabe temer que no sean tan controlables en buena parte de su inevitable incidencia.

\footnotetext{
${ }^{59}$ F. López de Oñate, La certezza del diritto, Giuffrè, Milán, 1968, pág. 140.

${ }^{60}$ M. Corsale, Certezza del diritto e crisis di legitimità, Giuffrè, 2a . edición, 1979, pág. 234.
} 
Siendo así, parece obvio que la certeza posible es una certeza dinámica, la certeza como resultado tendencial de la convergencia de una serie de refuerzos, de la operatividad de algunos resortes preventivos y reactivos, orientados a posibilitar otros tantos momentos de ejercicio de una racionalidad crítica explícita, destinados a desplazar lo que hoy son, tantas veces, formas de ocultación del ejercicio de algún grado de discrecionalidad abierta al arbitrio.

Una tal certeza nunca podría buscarse dando la espalda a los datos constitutivos del modo de ser actual del orden jurídico ${ }^{61}$ y del modus operandi que hacen posible. Por eso, frente a una cultura del encubrimiento o de la renuncia a hacer frente a esos datos, debe propugnarse y trabajarse por una cultura fundada sobre el conocimiento de los mismos y de la naturaleza efectiva de las prácticas que inducen. En lo que aquí interesa, por un reforzamiento sensible de la dimensión cognoscitiva de la función jurisdiccional, de la conciencia del carácter de los actos que la constituyen, de lo que en ellos pueda haber de ejercicio de un mayor o menor grado de poder, a veces escasamente vinculado. Así será posible, entre otras cosas, cumplir con eficacia democrática la exigencia de motivación ${ }^{62}$, entendida como el deber inexcusable de dar cuenta de las auténticas razones del acto o proceso de decisión, que preactúa garantizando una mejor calidad de éste en todas sus dimensiones.

${ }^{61}$ G. Zagrebelsky ha señalado que la superación del «déficit de certeza» que hoy acusan los sistemas jurídicos excede del campo de la interpretación, haciendo hincapié en la necesidad de «organizar esa tendencia a la transformación, intrínseca al ordenamiento, de modo que no resulte destructiva de otros valores». (Op. Cit., pág. 202).

${ }^{62}$ Esta exigencia cobra en la actualidad todavía mayor relevancia cuando se repara en la frecuencia con que el juez se ve obligado a actuar conforme a la lógica de lo razonable, en situaciones frecuentemente connotadas por la fluidez y elasticidad -a veces contradictoriedad- de los referentes normativos y la complejidad, atipicidad y conflictividad de muchos supuestos de hecho. De nuevo remito ahora para unas consideraciones sumamente lúcidas sobre el papel del juez en este contexto, a G. Zagrebelsky, op. cit., págs. 203 y ss., entre otras.

\section{$\triangle$

